Artigo original

Hegemonia - Revista Eletrônica do Programa de Mestrado em Direitos Humanos, Cidadania e Violência/Ciência Política do Centro Universitário Unieuro

ISSN: 1809-1261

UNIEURO, Brasília, número 23, Janeiro a Junho de 2018, pp. 55-77.

Recebido em: 22/8/2017

Avaliado em: 29/9/2017

Aprovado em: 30/10/2017

\title{
MENSURAÇÃO DA RENÚNCIA FISCAL NOS MECANISMOS DE REPACTUAÇÃO DE PASSIVOS TRIBUTÁRIOS COM A UNIÃO NO PERÍODO 2010-2013
}

Joaquim Ramalho de Alburquerque, ${ }^{1}$ Clesia Camilo Pereira, ${ }^{2}$ e Moisés Ferreira da Cunha ${ }^{3}$

RESUMO: O efeito das repactuações de valores devidos à União incide sobre duas políticas essenciais para as finanças da União: de um lado, pelo efeito das remissões, sobre a política tributária e de outro, pela arrecadação extraordinária proporcionada pelos pagamentos exigidos para a renegociação. Assim o objetivo deste estudo é investigar a participação das receitas extraordinárias da repactuação para o resultado primário do Governo Federal no quadriênio de 2010 a 2013. Para alcançar esse objetivo foi realizado um estudo descritivo com o intuito de identificar as receitas extraordinárias proporcionadas ao Tesouro Nacional pela consolidação de dívida de empresa ao Fisco Federal, e posterior repactuação, entre 2010 e 2013. Foram selecionadas cinco companhias com dívidas mais significativas parceladas. A verificação se deu por meio do levantamento de informações divulgadas nos relatórios de análise de arrecadação das receitas federais e nas demonstrações financeiras das companhias. Os resultados indicam que os valores envolvidos, a preços correntes, nas negociações abrangidas pelos programas de parcelamento alcançaram o montante de $\mathrm{R} \$ 21.785,5$ milhões em 2013 , de $\mathrm{R} \$ 2.800$ milhões em 2012, de R\$ 17.800 milhões em 2011 e de R\$ 8.766 milhões em 2010, contribuindo, respectivamente, com $28,29 \%, 3,16 \%, 19,13 \%$ e $11,13 \%$ para o cumprimento da meta fiscal do Governo Federal nesses anos. Por outro lado, os ganhos tributários da Vale do Rio Doce, da Cielo, do Bradesco, da Companhia Siderúrgica Nacional e da Petrobras perfizeram um total de R \$ 31.799 milhões a preços de dezembro de 2013. Importa destacar o tratamento diferenciado

\footnotetext{
${ }^{1}$ Doutorando em Ciências Contábeis pela Universidade de Brasília.

${ }^{2}$ Doutora em Ciências Contábeis e docente da Universidade de Brasília.

${ }^{3}$ Doutor em Controladoria e Contabilidade e docente da Universidade Federal de Goiás.
} 
Artigo original

Hegemonia - Revista Eletrônica do Programa de Mestrado em Direitos Humanos, Cidadania e Violência/Ciência Política do Centro Universitário Unieuro

ISSN: 1809-1261

UNIEURO, Brasília, número 23, Janeiro a Junho de 2018, pp. 55-77.

dado às pessoas jurídicas que fizeram opção pela inadimplência ou pela litigância tributária e posteriormente aderiram às reaberturas de prazos.

PALAVRAS-CHAVE: Renuncia Fiscal; Repactuação; Passivos Tributários; União.

ABSTRACT: The effect of value adjustments due to the Union is on two essential policies for the Union's finances: on the one hand, by the effect of remissions, on tax policy and on the other, by the extraordinary revenue provided by the payments required for renegotiation. Thus, the objective of this study is to investigate the share of the extraordinary revenue from the renegotiation of the primary income of the Federal Government in the four-year period from 2010 to 2013. To achieve this objective, a descriptive study was carried out to identify the extraordinary revenues provided to the National Treasury by consolidation of corporate debt to the Federal Treasury, and subsequent renegotiation between 2010 and 2013. Five companies with more significant debts were selected. The verification took place through the collection of information disclosed in the federal revenue collection analysis reports and in the companies' financial statements. The results indicate that the amounts involved, at current prices, in the negotiations covered by the installment programs reached $\mathrm{R} \$ 21,785.5$ million in 2013 , $\mathrm{R} \$ 2,800$ million in 2012, R \$ 17,800 million in 2011 and $\mathrm{R} \$ 8,766$ million in 2010, contributing, respectively, $28.29 \%, 3.16 \%, 19.13 \%$ and $11.13 \%$, respectively, to meeting the Federal Government's fiscal target in those years. On the other hand, the Vale do Rio Doce, Cielo, Bradesco, Companhia Siderúrgica Nacional and Petrobras tax earnings totaled R \$31,799 million at December 2013 prices. It is important to highlight the differential treatment given to legal entities who opted for delinquency or tax litigation and subsequently adhered to the reopening of deadlines.

KEYWORDS: Fiscal Resignation; Renegotiation; Tax Liabilities; and Unity.

\section{INTRODUÇÃO}

De acordo com Saravia (2001, p. 28) uma política pública é um fluxo de decisões públicas, orientado a manter o equilíbrio social ou a introduzir desequilíbrios destinados a modificar essa realidade.

No arcabouço normativo do Brasil são estabelecidas metas para as políticas monetária e fiscal. O indicador de meta fiscal é o resultado primário, equivalente à diferença entre receitas primárias e despesas primárias. Para a consecução da meta de resultado primário do Governo 
Artigo original

Hegemonia - Revista Eletrônica do Programa de Mestrado em Direitos Humanos, Cidadania e Violência/Ciência Política do Centro Universitário Unieuro

ISSN: 1809-1261

UNIEURO, Brasília, número 23, Janeiro a Junho de 2018, pp. 55-77.

Central duas escolhas de política pública apresentam efeitos opostos. No que se refere à política tributária, a possibilidade de parcelamento oferecida pela União às empresas pode e tem resultado em aumento da arrecadação extraordinária decorrente dessas negociações. Em sentido oposto, os parcelamentos têm efeito negativo sobre a eficiência da arrecadação tributária (Paes, 2014).

No quadriênio 2010/2013 normativos federais editados permitiram a empresas repactuarem os valores devidos à União. Uma exigência condicionante à aprovação era que se efetuasse o pagamento do principal ou o parcelamento percentual do principal e de parte das obrigações acessórias no exercício financeiro de adesão. Os prazos inicialmente estabelecidos foram sucessivamente reabertos, acarretando a adesão de empresas inadimplentes autuadas. Isso possibilitou a essas empresas a avaliação do custo benefício da adesão aos programas de parcelamento nos exercícios subsequentes.

O efeito dessas repactuações, que incluíram novos programas com diferentes tributos e sucessivas reaberturas de prazos de adesão, incide sobre duas políticas essenciais para as finanças da União. De um lado, pelo efeito das remissões, sobre a política tributária e de outro, pela arrecadação extraordinária proporcionada pelos pagamentos exigidos para a renegociação. $\mathrm{O}$ efeito dessa manobra não é trivial para a consecução da meta de resultado primário, principal indicador da política fiscal da União.

Aparentemente tal extravagância atende à necessidade do Governo Central de alcançar a meta fiscal, representada pelo superávit primário como percentual do Produto Interno Bruto (PIB). E, para sua consecução, formulou a Lei n. 12.865 (2013) cujo art. 17 respalda o governo na reabertura do prazo de parcelamentos de dívidas tributárias e previdenciárias no âmbito da Lei n. 11.941 (2009), no $\int 12$ do art. $1^{\circ}$ e art. $7^{\circ}$, e da Lei n. 12.249 (2010), no $\int 18$ do art. 65. O resultado dessa reabertura foram recolhimentos extraordinários no montante de R\$21.785,5 milhões, que correspondem a de 28\% do resultado primário alcançado no exercício de 2013.

Assim, considerando esse contexto, surge a seguinte questão de pesquisa: será que o valor arrecadado oriundo de receitas extraordinárias de repactuação está contribuindo significativamente para o superávit primário?

Assim, o objetivo deste estudo é investigar a participação das receitas extraordinárias da repactuação para o resultado primário do Governo Federal no quadriênio de 2010 a 2013. Para alcançar esse objetivo, foi realizado um estudo descritivo com o intuito de identificar as receitas extraordinárias proporcionadas ao Tesouro Nacional pela consolidação de dívidas de empresas ao Fisco Federal, e posterior repactuação, entre 2010 e 2013. Adicionalmente, releva mensurar a 
Artigo original

Hegemonia - Revista Eletrônica do Programa de Mestrado em Direitos Humanos, Cidadania e Violência/Ciência Política do Centro Universitário Unieuro

ISSN: $1809-1261$

UNIEURO, Brasília, número 23, Janeiro a Junho de 2018, pp. 55-77.

participação desses valores na consecução da meta de resultado primário do Governo Central dos respectivos exercícios.

Foram selecionadas cinco companhias com dívidas mais significativas parceladas, em dois setores da economia intensivos em capital financeiro e capital imobilizado. A verificação se deu por meio do levantamento de informações divulgadas nos relatórios de análise de arrecadação das receitas federais e nas demonstrações financeiras das companhias nos anos de 2010 a 2014.

Este trabalho tem sua relevância, pois o parcelamento de créditos tributários constitui importante instrumento de que a União dispõe para a recuperação de suas receitas. Ao final dos exercícios de 2010, 2011, 2012 e 2013 os créditos com exigibilidade suspensa atingiam, respectivamente, os montantes de $\mathrm{R} \$ 578,8$ bilhões (Tribunal de Contas da União, 2011), $\mathrm{R} \$$ 575,6 bilhões (Tribunal de Contas da União, 2012), R \$ 713,5 bilhões (Tribunal de Contas da União, 2013) e R 886 bilhões (Tribunal de Contas da União, 2014).

De acordo com o Tribunal de Contas da União (2014, p. 100), os parcelamentos convencional e especial são instrumentos de cobrança amigável de débitos tributários e previdenciários, e sua fungibilidade pode contribuir para o cumprimento das metas de arrecadação em apoio à consecução da meta de resultado primário do Governo Central. Adicionalmente, pelo seu efeito sobre a condição de adimplência dessas empresas com o Governo pode facilitar o acesso ao mercado de capitais e permitir sua continuidade em períodos de crescimento econômico menos vigoroso.

Este artigo está organizado em quatro seções, além dessa introdução, distribuídos da seguinte forma. A seção 2 apresenta o referencial teórico que serviu de embasamento ao estudo. A seção três apresenta a metodologia. A seção quatro faz uma análise dos principais achados na pesquisa. A seção 5 apresenta as considerações finais sobre o problema de pesquisa.

\section{REFERENCIAL TEÓRICO}

2.1 Comportamento nas Escolhas e Custo de Oportunidade

Ainda que a iniciativa de proposição legislativa em matéria tributária e em política fiscal seja predominantemente feita pelo Poder Executivo, nenhuma lei pode ser aprovada sem o escrutínio do Congresso, que exerce frequentemente seus poderes de modificar, vetar ou apoiar legislação instituidora de políticas públicas. Importa, portanto, verificar como se comporta o Congresso na produção legislativa relativa à política fiscal e às matérias tributárias. 
Artigo original

Hegemonia - Revista Eletrônica do Programa de Mestrado em Direitos Humanos, Cidadania e Violência/Ciência Política do Centro Universitário Unieuro

ISSN: $1809-1261$

UNIEURO, Brasília, número 23, Janeiro a Junho de 2018, pp. 55-77.

Em trabalho seminal, Arnold (1990) apresenta uma teoria de como o Congresso funciona. Por exemplo, por que algumas vezes são aprovadas leis beneficiando grupos específicos e em outras são aprovadas leis com benefícios difusos? $\mathrm{O}$ autor sugere que existem três níveis a serem considerados.

Os indivíduos tomam decisões sobre políticas públicas de maneira prospectiva, em que analisam quais serão os efeitos das políticas, ou retrospectiva, em que avaliam como imaginam que a política pública funcionou. Já os parlamentares tentam antecipar as preferências dos indivíduos; e como eles avaliam as ações dos congressistas quando votam na eleição. Líderes de coalizão tentam enquadrar questões levando em consideração esses cálculos feitos pelos parlamentares, tornando mais fácil votar por uma proposição particular. Os líderes de coalizão podem usar a persuasão, procedimentos ou emendas para ajudar a construir suporte para um normativo particular.

A principal variável para explicar as decisões do Congresso são as normas regimentais, que permitem a aprovação de benefícios difusos sem a identificação dos responsáveis pelas escolhas dessas políticas com custos concentrados. Mas, essas mesmas regras podem servir para a aprovação de benefícios concentrados com custos difusos.

Deputados e senadores desejam aprovar políticas com benefícios concentrados e custos difusos, mas os eleitores desejam políticas com benefícios difusos (e talvez com custos concentrados sobre outros eleitores). Portanto, interessa indagar por que o Congresso algumas vezes aprova proposições que atendem a interesses organizados. E, em outras vezes, aprova aquelas que atendem a um público mais alargado. De igual modo, por que algumas vezes parece favorecer benefícios geográficos, mas outras vezes direciona-se para benefícios a grupos mais amplos?

\subsection{Política econômica}

De acordo com Arnold, 1990, existe uma distinção importante entre política econômica explícita e política econômica derivada. A primeira é uma política proposta para resolver um problema macroeconômico específico, tal como a política fiscal. Nesse caso, a ênfase é sobre custos e benefícios gerais e não sobre custos e benefícios de grupos. A segunda é proposta para melhorar alguma outra condição, ainda que também tenha efeitos macroeconômicos, tal como as renúncias fiscais. Agora, a ênfase é sobre custos e benefícios de grupos ao invés de focar sobre custos e benefícios gerais. 
Artigo original

Hegemonia - Revista Eletrônica do Programa de Mestrado em Direitos Humanos, Cidadania e Violência/Ciência Política do Centro Universitário Unieuro

ISSN: 1809-1261

UNIEURO, Brasília, número 23, Janeiro a Junho de 2018, pp. 55-77.

Também é recomendável agrupar muitas alterações de forma que grupos organizados não sejam atingidos um de cada vez. Votações abertas tornam difíceis cortes de tributos, porque legisladores tendem a votar pela manutenção ou aumento de desonerações tributárias para grupos particulares quando sendo atentamente monitorados. Sessões abertas ao público beneficiam grupos que podem monitorar os procedimentos mais de perto que o público não atento.

\subsection{Política tributária}

Alguns estranham como é possível que legisladores algumas vezes aumentem tributos, quando isso parece ser uma atividade muito impopular. A tributação gradualmente expande sua incidência sobre pessoas, e a inflação empurra as pessoas para faixas mais elevadas de tributação. Em geral, aumentos de tributos requerem votações em sessões fechadas ou secretas, assegurando aos legisladores que seus votos não podem ser ligados aos aumentos.

Tendo em vista a lógica apresentada, é importante entender o efeito que a tomada de decisão dos cidadãos tem sobre os legisladores. Os cidadãos podem usar a regra do desempenho do partido ou a regra da posição do partido. Isto é, quando existe um conflito entre um legislador individual e o partido dele, ele procura se apresentar melhor pessoalmente, ao invés de ter um pequeno efeito marginal para melhorar o desempenho do partido, uma vez que eles não podem fazer muito para afetar os votos dos cidadãos de qualquer maneira. Os cidadãos podem usar a regra do desempenho do incumbente ou a regra da posição do candidato. Nesse caso os legisladores devem tentar evitar votar em matérias que sejam impopulares e que possam ser conectadas às suas ações.

Contudo, para quais cidadãos os legisladores dão atenção varia. Ao votar sobre questões específicas, ele pode ser mais atento a interesses de grupos, de forma que os cidadãos podem ser prejudicados (ou não obter os benefícios que poderiam obter). É importante destacar que legisladores consideram preferências potenciais quando políticas públicas podem ter um grande efeito sobre os cidadãos.

Portanto o que deve ser levado em conta ao observar a lista de votação para entender o que legisladores decidem, é considerar quais matérias avançam antes da votação começar. É possível que grupos de interesse e considerações de preferências potenciais tenham um efeito sobre quais matérias têm sucesso na agenda - coisas que sejam controversas ou impopulares ao público podem não ser consideradas em primeiro lugar.

Para dar visibilidade ao impacto das escolhas dos legisladores esse estudo procura demonstrar a arrecadação extraordinária proporcionada pelos programas de parcelamentos de dívidas de empresas de capital aberto, sua contribuição para a consecução das metas de resultado 
Artigo original

Hegemonia - Revista Eletrônica do Programa de Mestrado em Direitos Humanos, Cidadania e Violência/Ciência Política do Centro Universitário Unieuro

ISSN: $1809-1261$

UNIEURO, Brasília, número 23, Janeiro a Junho de 2018, pp. 55-77.

primário do Governo Central, assim como os ganhos tributários das empresas decorrentes dos parcelamentos de débitos tributários.

Existem alguns custos, relacionados aos procedimentos de parcelamento, que devem ser levados em consideração nos casos de tomada de decisão e que não são contabilizados nos custos registrados. Quando um recurso é usado para financiar certa atividade, seu uso alternativo não é possível, o que pode conduzir a benefícios não realizados. Conforme Budding, Grossi \& Tagesson (2015, p. 110), o custo de oportunidade é o benefício descartado que poderia ter se realizado pelo uso do recurso na melhor alternativa desprezada. Dessa maneira, faz sentido atentar para o custo de oportunidade da perda tributária decorrente do parcelamento.

\subsection{Estudos Relacionados ao Tema Repactuação de Passivos}

Usando dados do período que se estende de 2005 a 2010, Cavalcante (2010) demonstra uma correlação negativa entre a arrecadação tributária convencional e aquela conseguida pelos parcelamentos especiais. $\mathrm{O}$ autor também concluiu que a arrecadação convencional não possui correlação com o nível da atividade econômica e nem com a taxa de juros livre de risco.

Morais, Macedo \& Borges (2011) demonstram que os parcelamentos tributários são ineficientes do ponto de vista da arrecadação, uma vez que $90 \%$ do estoque parcelado não é pago. E essa diminuição decorre da adesão aos novos parcelamentos que são instituídos trienalmente e, mais recentemente, a cada dois anos. De acordo com os autores também a cobrança administrativa de débitos tributários tem relação negativa com as sucessivas reaberturas de parcelamentos. Daí a diminuição dos índices de recuperação de crédito tributário no Brasil.

Mendes (2012) identificou os controles existentes e oportunidades de melhoria desses controles sobre ações governamentais baseadas em renúncia de receita. A partir de pesquisa bibliográfica, documental e aplicada o autor concluiu que a comparação entre renúncias de receita e despesas orçamentárias de características de execução semelhante pode representar um aperfeiçoamento dos controles exercidos sobre a renúncia proporcionada pelos gastos tributários.

Fundamentado em um modelo teórico para análise de comportamento do contribuinte tendo em vista o parcelamento tributário, Paes (2011) conclui que a expectativa de futuros parcelamentos tributários altera a propensão a pagar de tributos pelo contribuinte no presente. A elevação do número de parcelas e a correção por taxas de juros menores são os instrumentos que acarretam maiores aumentos de evasão fiscal. 
Artigo original

Hegemonia - Revista Eletrônica do Programa de Mestrado em Direitos Humanos, Cidadania e Violência/Ciência Política do Centro Universitário Unieuro

ISSN: 1809-1261

UNIEURO, Brasília, número 23, Janeiro a Junho de 2018, pp. 55-77.

Paes (2014) avaliou o impacto que os programas de parcelamento tributário exercem sobre o comportamento do contribuinte e sobre a arrecadação. Sem a concessão de parcelamentos o hiato tributário alcança 30\%, expandindo-se para 34\% em vista dos parcelamentos concedidos. O autor concluiu pelo estímulo negativo e reiterado dos sucessivos parcelamentos exercido sobre a espontaneidade do contribuinte. Os resultados de seus estudos permitem dizer que o parcelamento é inadequado como mecanismo de aumento de arrecadação e de incentivo aos contribuintes.

$\mathrm{Na}$ literatura referente a renúncias concedidas por parcelamentos de tributos, portanto, é predominante a visão da inadequação dessa política tributária. De acordo com Paes (2014, p. 328), isso decorre do impacto negativo dos programas de parcelamentos sobre o cumprimento espontâneo da obrigação tributária e da baixa eficiência sobre a arrecadação.

\section{METODOLOGIA}

Segundo Gil (2002, p. 17), uma pesquisa é um procedimento racional e sistemático que tem como objetivo proporcionar respostas aos problemas que são propostos. Assim, sabendo que toda e qualquer classificação se faz mediante algum critério e com relação às pesquisas, é usual classificá-las com base em seus objetivos gerais (Gil, 2002, p.41) e quanto ao delineamento (Gil, 2002, p.43).

Considerando este contexto, para atender ao objetivo proposto, por meio de uma pesquisa descritiva, qualitativa e documental, primeiramente buscou-se verificar o montante das arrecadações extraordinárias ocorridas em função da renegociação e, logo a seguir, analisou-se o conteúdo das Demonstrações Financeiras Padronizadas (DFP), divulgadas no sítio da BM\&FBOVESPA, referentes ao exercício de 2010 a 2013 das empresas da amostra.

De acordo com o art. 151 do Código Tributário Nacional (Lei n. 5.172, 1966), suspendem a exigibilidade do crédito tributário, mas não obrigatórios, tanto o depósito de seu montante integral quanto o seu parcelamento. Adicionalmente, de acordo com o mesmo normativo, não é vedada a divulgação de informações relativas ao parcelamento (art. 198, \ $3^{\circ}$ inciso III). No entanto, nas publicações do Ministério da Fazenda não é possível identificar os montantes renegociados pelo número do Cadastro Nacional de Pessoa Jurídica (CNPJ).

Por essa razão foi necessário conciliar os valores renegociados por empresas (publicados em suas demonstrações contábeis e notas explicativas) a partir dos montantes consolidados explicitados no documento "Análise de Arrecadação das Receitas Tributárias" publicado 
Artigo original

Hegemonia - Revista Eletrônica do Programa de Mestrado em Direitos Humanos, Cidadania e Violência/Ciência Política do Centro Universitário Unieuro

ISSN: 1809-1261

UNIEURO, Brasília, número 23, Janeiro a Junho de 2018, pp. 55-77.

mensalmente pela Receita Federal do Brasil (RFB). Os montantes foram cotejados com informações fornecidas pelos respectivos responsáveis por relacionamento com investidores dos valores renegociados com a RFB de grandes empresas dos setores de mineração, financeiro, siderurgia, petróleo e gás.

Nas demonstrações, notas e informações do setor de relações com investidores identificaram-se o registro das provisões e dos montantes renegociados pelas empresas, de acordo com o critério de balanço consolidado. A arrecadação extraordinária do Tesouro Nacional foi obtida no mencionado documento da RFB. Os resultados primários foram obtidos no documento "Resultado Fiscal do Governo Central" da Secretaria do Tesouro Nacional. Tanto os valores renegociados das empresas quanto a arrecadação extraordinária foram convertidos em percentuais do PIB para cada exercício.

Um aspecto importante do procedimento administrativo fiscal é que depósitos judiciais e extrajudiciais são transferidos pelas instituições financeiras à conta única do Tesouro Nacional na mesma data da transferência de pagamentos normais de tributos, independente da tramitação em julgado da lide fiscal. É certo que, na eventualidade de impugnação da cobrança, o mesmo Tesouro tem vinte e quatro horas para a devolução do principal, ajustado pela taxa Selic ao contribuinte, conforme inciso I do art. $2^{\circ}$ do Decreto n. 2.850 (1998).

No caso em que o contribuinte desiste da impugnação e faz a opção pela consolidação de sua dívida tributária, os parcelamentos dos programas permitem descontos de até cem por cento das multas de mora e de ofício, quarenta e cinco por cento dos juros de mora e cem por cento dos encargos legais. Isso está condicionado ao pagamento à vista, mas há condições também vantajosas para parcelamento em até 180 meses, com a possibilidade de utilização dos depósitos judiciais efetuados pelas empresas no pagamento à vista.

Não menos importante, a reabertura dos parcelamentos permitiu a utilização de percentuais de prejuízos fiscais e bases negativas de contribuição social sobre o lucro das pessoas jurídicas para abatimento das dívidas consolidadas.

Efetuaram-se consulta às demonstrações contábeis de grandes empresas de capital aberto, à legislação específica sobre o tema tributário e fiscal e às publicações da Secretaria do Tesouro Nacional e da Receita Federal do Brasil do Ministério da Fazenda. Uma vez identificados os valores renegociados e os benefícios tributários obtidos comparam-se essas cifras com o Produto Interno Bruto e com o resultado primário do Governo Central.

Uma das limitações do presente estudo trata-se da dificuldade de visualização do valor integral renegociado em função dos critérios de contabilização e divulgação das informações 
Artigo original

Hegemonia - Revista Eletrônica do Programa de Mestrado em Direitos Humanos, Cidadania e Violência/Ciência Política do Centro Universitário Unieuro

ISSN: 1809-1261

UNIEURO, Brasília, número 23, Janeiro a Junho de 2018, pp. 55-77.

contábeis. Conforme Procedimento Técnico CPC 25 (2009) há uma distinção clara entre provisões e passivos contingentes. As provisões são contabilizadas e os passivos podem (se a saída de recursos é possível), ou não (quando a probabilidade de saída de recursos é remota), integrar as notas explicativas.

Regra geral, as empresas dividem suas provisões e passivos contingentes em processos massificados e em processos individualizados. Os primeiros são relativos às causas consideradas semelhantes e de valor individual pouco relevante. Os segundos são relativos às causas com características peculiares ou de valor relevante. Uma vez que as empresas adotam procedimentos diferentes dependendo da apreciação de seus setores jurídicos sobre a possibilidade de ganho em decisão administrativa ou judicial, algumas delas não registram tempestivamente os provisionamentos, até que a despesa se torne iminente.

Adicionalmente, há um juízo de valor tanto na probabilidade de ocorrência ou não do evento contingente, quanto na mensuração, que muitas vezes envolve aspectos tributários controversos com múltiplas formas de estimação. Em qualquer dessas hipóteses, após a autuação a empresa pode recorrer do procedimento seja em foro administrativo, como em foro judicial.

\subsection{Arrecadação Extraordinária}

De acordo com o documento publicado pela Receita Federal do Brasil denominado “Análise da Arrecadação das Receitas Federais", em decorrência dos programas de parcelamento de dívidas, houve arrecadação extraordinária de $\mathrm{R} \$ 21.785,5$ milhões em 2013, R $\$ 2.800$ milhões em 2012, R\$ 17.890 milhões em 2011 e R 3.466 milhões em 2010, conforme apresentado na Tabela 1. 
Artigo original

Hegemonia - Revista Eletrônica do Programa de Mestrado em Direitos Humanos, Cidadania e Violência/Ciência Política do Centro Universitário Unieuro

ISSN: $1809-1261$

UNIEURO, Brasília, número 23, Janeiro a Junho de 2018, pp. 55-77.

Tabela 1: Receitas Atípicas do Governo Central, no período de 2010 a 2013, com valores expressos em milhões

\begin{tabular}{|c|c|c|c|}
\hline Receita & Período & Valor & Descrição \\
\hline IRPJ & \multirow{5}{*}{2013} & $1.422,3$ & Reabertura Lei n. 11.941 (2009) (art. 17). \\
\hline PIS/Cofins & & $12.077,6$ & Entidades financeiras (art. 39) \\
\hline PIS/Cofins & & 616,2 & Exclusão do ICMS da base de cálculo do PIS/Cofins (art. 39 S $1^{\circ}$ ). \\
\hline IRPJ/CSLL & & $7.669,4$ & $\begin{array}{l}\text { Reabertura de prazos para pagamento de débitos decorrentes de lucros no } \\
\text { exterior ocorridos até } 31 / 12 / 2012 \text { (art. 40). }\end{array}$ \\
\hline Total - 2013 & & $21.785,5$ & \\
\hline IRPJ & \multirow{2}{*}{2012} & $2.800,0$ & Reclassificação de IRPJ. \\
\hline Total - 2012 & & $2.800,0$ & \\
\hline CSLL & \multirow{4}{*}{2011} & $5.800,0$ & $\begin{array}{l}\text { Recolhimento, em julho de } 2011 \text {, de débito em atraso, relativamente à CSLL } \\
\text { em razão de encerramento de questionamento na esfera judicial. }\end{array}$ \\
\hline \multirow[t]{2}{*}{ IRPJ } & & $6.700,0$ & $\begin{array}{l}\text { Consolidação/antecipação de parcelas, em especial no período de junho a } \\
\text { agosto, de débitos parcelados em conformidade com a Lei n. } 11.941 \text { (2009). }\end{array}$ \\
\hline & & $5.390,0$ & Reclassificação de IRPJ e o IPI. \\
\hline Total - 2011 & & $17.890,0$ & \\
\hline PIS/PASEP & \multirow{4}{*}{2010} & $4.200,0$ & $\begin{array}{l}\text { Arrecadação extraordinária em função de depósito judicial efetuado por } \\
\text { entidade financeira, no valor de R\$ } 4 \text { bilhões, em dezembro de } 2010 \text {. }\end{array}$ \\
\hline IRPJ e IPI & & $3.466,0$ & Reclassificação para o IRPJ e o IPI. \\
\hline CSLL & & $1.100,0$ & Arrecadação atípica em dezembro. \\
\hline Total -2010 & & $8.766,0$ & \\
\hline
\end{tabular}

\section{ANÁLISE DOS RESULTADOS}

A Tabela 2 discrimina a arrecadação extraordinária proporcionada pelos parcelamentos e o resultado primário alcançado a cada ano pelo Governo Central, em valores correntes e como percentual do Produto Interno Bruto, assim como a contribuição da arrecadação extraordinária para a obtenção do resultado primário do Governo Central. A média da participação da arrecadação extraordinária na obtenção do resultado primário é de 15,43\%, com desvio-padrão de 10,77 e mediana de $15,13 \%$. 
Artigo original

Hegemonia - Revista Eletrônica do Programa de Mestrado em Direitos Humanos, Cidadania e Violência/Ciência Política do Centro Universitário Unieuro

ISSN: $1809-1261$

UNIEURO, Brasília, número 23, Janeiro a Junho de 2018, pp. 55-77.

Tabela 2: Arrecadação extraordinária proporcionada pelos parcelamentos e o resultado primário

\begin{tabular}{cccccc}
\hline Exercício & Arrec Extraord (A) & \% do PIB & Resul prim GC (B) & \% do PIB & (A) /(B) \% \\
\hline 2013 & $21.785,5$ & 0,42 & $77.000,0$ & 1,49 & 28,29 \\
2012 & $2.800,0$ & 0,06 & $88.528,9$ & 1,87 & 3,16 \\
2011 & $17.890,0$ & 0,41 & $93.524,6$ & 2,13 & 19,13 \\
2010 & $8.766,0$ & 0,23 & $78.772,9$ & 2,03 & 11,13 \\
\hline
\end{tabular}

Fonte: STN, RFB.

Tendo em vista a soma de $\mathrm{R} \$ 31.799$ milhões de benefícios tributários conseguidos no exercício de 2013 pelas cinco grandes empresas consideradas, constata-se que o valor constitui 0,62\% do Produto Interno Bruto e 41,3\% do resultado primário obtido pelo Governo Central. Portanto, ao tempo em que essas renegociações resolvem o problema de caixa do Tesouro Nacional facultando a consecução da meta de resultado primário, representam uma renúncia de receita substantiva que deixa de entrar nos cofres da União. Adicionalmente, o procedimento de repactuação cria mecanismos de incentivo para a diminuição da arrecadação tributária federal.

A arrecadação extraordinária proporcionada pelos parcelamentos sucessivamente editados pela União alcançou, respectivamente, os valores de $\mathrm{R} \$ 21.785,5$ milhões, $\mathrm{R} \$ 2.800$ milhões, $\mathrm{R} \$$ 17.890 milhões e R $\$ 8.766$ milhões, a preços correntes respectivos, nos exercícios de 2013, 2012, 2011 e 2010. Esses montantes representaram 28,29\%, 3,16\%, 19,13\% e 11,13\%, respectivamente, para os exercícios mencionados, do resultado primário do Governo Central, numa média anual de $15,43 \%$ da meta alcançada. Ou seja, sem o auxílio dessa repactuação as metas de resultado fiscal não teriam sido alcançadas.

Somente no exercício de 2013, o benefício tributário obtido por cinco grandes empresas de capital aberto atuantes nos setores de mineração, financeiro, siderurgia e de petróleo alcançou a cifra de R $\$ 31.799$ milhões. As empresas Vale do Rio Doce, Cielo, Bradesco, Companhia Siderúrgica Nacional e Petrobrás foram beneficiadas com o parcelamento nos montantes $\mathrm{R} \$$ 22.778 milhões, $\mathrm{R} \$ 4.821$ milhões, $\mathrm{R} \$ 1.950$ milhões, de $\mathrm{R} \$ 1.267$ milhões e $\mathrm{R} \$ 983$ milhões. Portanto, tendo em vista o referencial de resultado primário obtido no exercício de 2013, o montante representa $0,62 \%$ do PIB e $41,3 \%$ da meta fiscal do Governo Central. A seguir, a análise individual dessas empresas. 
Artigo original

Hegemonia - Revista Eletrônica do Programa de Mestrado em Direitos Humanos, Cidadania e Violência/Ciência Política do Centro Universitário Unieuro

ISSN: $1809-1261$

UNIEURO, Brasília, número 23, Janeiro a Junho de 2018, pp. 55-77.

\subsection{Montantes Renegociados}

Conforme definido nas Normas Brasileiras de Contabilidade do Setor Público - NBCTSP 16.11 (2011), “custo de oportunidade é o custo objetivamente mensurável da melhor alternativa desprezada relacionada à escolha adotada". Importa mensurar qual é o ganho das empresas com a repactuação no âmbito do REFIS e qual a contribuição dos pagamentos extraordinários para o cumprimento da meta de resultado primário do Governo Central no exercício de 2013. As demonstrações financeiras das empresas apresentam os valores decorrentes da negociação, a prestação única ou o montante inicial e as parcelas subsequentes, assim como o benefício tributário envolvido na negociação.

\subsubsection{Companhia Vale do Rio Doce}

A partir das demonstrações contábeis do exercício de 2012, a empresa reconhece, na nota explicativa 18 (pág. 46), débito com a União no montante de $\mathrm{R} \$ 31$ bilhões, dos quais $\mathrm{R} \$ 12$ bilhões de principal e $\mathrm{R} \$ 19$ bilhões de juros e multas. Trata-se de processo tributário classificado como de risco de perda possível, a cobrança do Imposto de Renda Pessoa Jurídica (IRPJ) e da Contribuição Social sobre o Lucro de Pessoa Jurídica (CSLL), incidente no resultado positivo de suas controladas e coligadas no exterior, reconhecidas pelo método da equivalência patrimonial.

Um programa específico de parcelamento para o pagamento de débitos de IRPJ e CSLL, vencidos até o final do exercício de 2012, foi instituído pelo art. 40 da Lei n. 12.865 (2013). Ele abrange os passivos fiscais decorrentes do art. 74 da Medida Provisória n. 2.158-35 (2001), que estabelece a tributação automática, ao término de cada exercício, de lucros auferidos por sociedades controladas ou coligadas com sede fora do país.

No escopo desse parcelamento há duas formas de escalonamento dos débitos vencidos. No primeiro caso, em que ocorre o pagamento à vista, são integralmente perdoadas as multas de 
Artigo original

Hegemonia - Revista Eletrônica do Programa de Mestrado em Direitos Humanos, Cidadania e Violência/Ciência Política do Centro Universitário Unieuro

ISSN: 1809-1261

UNIEURO, Brasília, número 23, Janeiro a Junho de 2018, pp. 55-77.

mora e de ofício, as multas isoladas, os juros de mora e os encargos legais. No segundo caso, em que o contribuinte deve pagar vinte por cento do valor total do débito em uma entrada e o restante em até 180 parcelas mensais.

Em novembro de 2013 a Companhia aderiu ao programa de parcelamento REFIS, envolvendo substancialmente todas as reivindicações relacionadas à cobrança de imposto de renda e contribuição social sobre o ganho de capital próprio de controladas e coligadas no exterior, cujas expectativas de perda estavam classificadas como possíveis pelo Conselho de Administração.

Entre as opções oferecidas pelo REFIS, a Companhia escolheu o pagamento antecipado dos débitos referentes aos anos de 2003, 2004 e 2006. Para os exercícios de 2005 e 2007 a 2012 a opção foi pelo pagamento em parcelas do principal, multas e juros. Considerando os pagamentos antecipados e da primeira parcela, foram desembolsados R $\$ 6.000$ milhões em 2013, enquanto os restantes $\mathrm{R} \$ 16.222$ milhões foram escalonados em 178 parcelas mensais.

O montante em discussão com o Fisco, com seus acréscimos, era de R $\$ 45.000$ milhões em dezembro de 2013. Desse valor houve um benefício tributário de R 22.778 milhões. Portanto, somente com uma empresa e relativo ao IRPJ e CSSL, o valor de face dos débitos em consequência do parcelamento foi deduzido de $\mathrm{R} \$ 45.000$ milhões para o valor de $\mathrm{R} \$ 22.222$ milhões.

\subsubsection{Cielo}

A companhia e sua controlada aderiram ao Programa de Pagamento ou Parcelamento de Débitos Tributários Federais, instituído pela Lei n. 11.941 (2009), cujo prazo de adesão foi estendido pela Lei n. 12.865 (2013). Seis processos tributários foram pagos na modalidade de pagamento à vista, aplicando-se as deduções permitidas (cem por cento das multas de mora e de ofício, $45 \%$ dos juros de mora e 100\% dos encargos legais), sendo que três dos processos possuíam depósito vinculado, para os quais foi requerida a conversão em renda da União. 
Artigo original

Hegemonia - Revista Eletrônica do Programa de Mestrado em Direitos Humanos, Cidadania e Violência/Ciência Política do Centro Universitário Unieuro

ISSN: $1809-1261$

UNIEURO, Brasília, número 23, Janeiro a Junho de 2018, pp. 55-77.

No balanço consolidado foram registrados pagamentos de $\mathrm{R} \$ 1.408$ milhões e a conversão dos depósitos em renda da União no montante de $\mathrm{R} \$ \mathrm{R} \$ 7.100$ milhões. O efeito resultante da reversão da provisão dos processos e do reconhecimento dos débitos no âmbito do REFIS teve impacto sobre o resultado do exercício, a título de despesa, em R $\$ 6.526$ milhões. O total de desconto obtido foi de $\mathrm{R} \$ 4.821$ milhões no consolidado.

\subsubsection{Bradesco}

Em novembro de 2013, o Bradesco aderiu ao programa de parcelamento e pagamento à vista de débitos tributários, com anistia para liquidação de débitos administrados pela Receita Federal do Brasil e pela Procuradoria Geral da Fazenda Nacional, instituído pela Lei no 12.865 (2013). São débitos relativos à contribuição para o Programa de Integração Social (PIS) e à Contribuição para o Financiamento da Seguridade Social (Cofins), de que trata o capítulo I da Lei n. 9.718 (1998), devidos por instituições financeiras e companhias seguradoras. O banco utilizou a prerrogativa do art. 17 da Lei n. 12.865 (2013), que reabriu, até 31 de dezembro de 2013, o prazo para adesão ao programa previsto na Lei n. 11.941 (2009). O benefício tributário conjunto alcançou o montante de $\mathrm{R} \$ 1.950$ milhões.

\subsubsection{Companhia Siderúrgica Nacional}

Pelo art. 40 da Lei n. 12.865 (2013), o governo federal permitiu o parcelamento de IRPJ e CSLL oriundos da aplicação do art. 74 da Medida Provisória n. 2.158-35 (2001), mais conhecido como lucros no exterior, que determina a tributação dos lucros auferidos por sociedades controladas ou coligadas sediadas no exterior ao final de cada ano.

A companhia optou pela adesão dos valores correspondentes ao período autuado (20042009), em 29 de novembro de 2013. Ambos os programas preveem reduções de multas e juros. No entanto somente os débitos de IRPJ e CSLL oriundos da Lei n. 12.865 (2013) puderam ser 
Artigo original

Hegemonia - Revista Eletrônica do Programa de Mestrado em Direitos Humanos, Cidadania e Violência/Ciência Política do Centro Universitário Unieuro

ISSN: 1809-1261

UNIEURO, Brasília, número 23, Janeiro a Junho de 2018, pp. 55-77.

liquidados com crédito fiscal decorrente de saldos de prejuízo fiscal e base negativa de CSLL de controladas e controladora. O valor de crédito fiscal utilizado das controladas alcança o montante de $\mathrm{R} \$ 565.273$ milhões, dos quais $\mathrm{R} \$ 550.270$ milhões não possuíam crédito fiscal constituído.

O valor dos débitos era de $\mathrm{R} \$ 1.895$ mil, mas com o parcelamento houve um benefício tributário de R $\$ 1.267$ milhões. O saldo remanescente foi parcelado em 180 meses atualizados pela taxa Selic e os valores apurados de acordo com as Leis n. 11.941 (2009) e 12.865 (2013).

\subsubsection{Petróleo Brasileiro S.A.}

A Petrobras aderiu em dezembro de 2013 ao REFIS aproveitando-se dos benefícios advindos das Leis n. 11.941 (2009) e 12.249 (2010), cujos prazos foram reabertos pela Lei n. 12.865 (2013). Os débitos incluídos no REFIS referem-se às autuações fiscais relativas aos tributos Contribuição sobre a Intervenção no Domínio Econômico, Imposto de Importação, Imposto sobre Produtos Industrializados, Imposto sobre Operações Financeiras, Imposto de Renda Retido na Fonte e Contribuição para o Financiamento da Seguridade Social. Com a adesão ao programa, a companhia desistiu das respectivas ações judiciais e administrativas de contestação dos débitos.

O desembolso efetivo foi de R 1.297 milhões, além da solicitação para utilização de depósitos judiciais de $\mathrm{R} \$ 39$ milhões, totalizando o montante de $\mathrm{R} \$ 1.336$ milhões. A economia tributária decorrente da adesão ao programa foi de $\mathrm{R} \$ 983$ milhões, em razão dos descontos de multas e juros previstos na legislação.

\section{CONSIDERAÇÕES FINAIS}

O presente estudo teve como objetivo aferir a participação das receitas extraordinárias decorrentes da repactuação de dívidas de empresas na consecução da meta de resultado primário do Governo Federal no quadriênio de 2010 a 2013. Adicionalmente, buscou-se identificar, nas 
Artigo original

Hegemonia - Revista Eletrônica do Programa de Mestrado em Direitos Humanos, Cidadania e Violência/Ciência Política do Centro Universitário Unieuro

ISSN: 1809-1261

UNIEURO, Brasília, número 23, Janeiro a Junho de 2018, pp. 55-77.

empresas com maiores consolidações de dívida na repactuação com a Secretaria da Receita Federal, o montante do benefício tributário envolvido, o valor da prestação única e/ou os montantes parcelados no exercício de 2013.

Após análise dos dados verifica-se que os valores envolvidos, a preços correntes, nas renegociações abrangidas pelos programas de parcelamento alcançaram o montante de $\mathrm{R} \$$ 21.785,5 milhões em 2013, de $\mathrm{R} \$ 2.800$ milhões em 2012, de $\mathrm{R} \$ 17.890$ milhões em 2011 e de $\mathrm{R} \$$ 8.766 milhões em 2010. Essas receitas atípicas ou extraordinárias contribuíram com respectivamente, $28,29 \%, 3,16 \%, 19,13 \%$ e $11,13 \%$ para o cumprimento da meta fiscal do Governo Central nesses anos.

Por outro lado, os ganhos tributários da Vale do Rio Doce, da Cielo, do Bradesco, da Companhia Siderúrgica Nacional e da Petrobrás foram, respectivamente, de R 22.778 milhões, de $\mathrm{R} \$ 4.821$ milhões, de $\mathrm{R} \$ 1.950$ milhões, de 1.267 milhões e de $\mathrm{R} \$ 983$ milhões, perfazendo um total de $\mathrm{R} \$ 31.799$ milhões a preços de dezembro de 2013. O benefício tributário auferido por essas empresas não ingressará nos cofres públicos e constitui ganho efetivo, das companhias que realizaram a provisão, a compor o resultado do período da repactuação.

Nesse contexto, importa ressaltar o tratamento diferenciado dado às pessoas jurídicas que fizeram opção pela inadimplência ou pela litigância tributária e posteriormente aderiram às reaberturas de prazo dos programas de parcelamentos de tributos atrasados e/ou contestados. Essas empresas foram beneficiadas pela diminuição de cobrança dos encargos e puderam alongar os prazos de pagamento. Posteriormente, pelo reconhecimento parcial das provisões em vista do benefício fiscal concedido nos parcelamentos puderam apresentar um melhor resultado operacional.

Em paralelo, os contribuintes que fizeram o pagamento no vencimento e sem questionamento são estimulados a não fazerem o pagamento tempestivo, uma vez que observam a diminuição dos encargos aplicáveis aos atrasos concedidos às empresas inadimplentes. A diminuição dos encargos pode estimular a utilização dos recursos não recolhidos ao Tesouro como capital de giro das empresas, tendo em vista o custo do capital eventualmente necessário para manter as operações.

Do ponto de vista das empresas esses sucessivos parcelamentos representam uma forma de diminuir a tributação pela redução do passivo tributário das empresas e consequente 
Artigo original

Hegemonia - Revista Eletrônica do Programa de Mestrado em Direitos Humanos, Cidadania e Violência/Ciência Política do Centro Universitário Unieuro

ISSN: $1809-1261$

UNIEURO, Brasília, número 23, Janeiro a Junho de 2018, pp. 55-77.

diminuição do valor a ser pago à União. Da parte da União essa escolha é incoerente dado que essas medidas acarretam ineficiência na arrecadação, pelo aumento do hiato tributário; premiam as empresas que não cumprem os prazos e penalizam as adimplentes.

Outra consequência dessas medidas é a injustiça. Isso se configura no incentivo à procrastinação de pagamentos de receitas da União pelas empresas. E se configura também ao induzir a se beneficiarem da contestação ao procedimento tributário, com reflexos desastrosos na arrecadação subsequente. Tipo de administração de fluxo de caixa exercido pelo Ministério da Fazenda que traz perda ao Erário e incentiva o descumprimento das obrigações principais das empresas com o pagamento dos tributos e contribuições. Tal renegociação privou o Governo Central de receitas que poderiam ter sido aplicadas em políticas sociais, na redução da carga tributária ou na diminuição do estoque da dívida pela geração de um resultado primário mais elevado.

\section{REFERÊNCIAS}

Arnold, R. D. (1990). The Logic of Congressional Action. New York: Vail-Ballou Press.

Budding, T.; Grossi, G. \& Tagesson, T. (2015). Public Sector Accounting (1a ed.) New York: Routledge.

Cavalcante, R. (2010). Estudo Exploratório Acerca da Influência do Parcelamento de Débitos sobre a Arrecadação Tributária da União. Monografia de Especialização, Instituto Serzedello Corrêa ISC/TCU, Brasília, DF, Brasil. Recuperado em 30 março, 2015, de http://portal2.tcu.gov.br/portal/docs/2293025.PDF.

Decreto n. 2.850, de 27 de novembro de 1998. (1998). Disciplina os procedimentos pertinentes aos depósitos judiciais e extrajudiciais, de valores de tributos e contribuições federais administrados pela Secretaria da Receita Federal, de que trata a Lei no 9.703, de 17 de novembro de 1998. Recuperado em 15 abril, 2015, de http://www.planalto.gov.br/ccivil_03/decreto/D2850.htm

GIL, A. C. (2002). Como elaborar projetos de pesquisa (4a ed.). São Paulo: Atlas. 
Artigo original

Hegemonia - Revista Eletrônica do Programa de Mestrado em Direitos Humanos, Cidadania e Violência/Ciência Política do Centro Universitário Unieuro

ISSN: 1809-1261

UNIEURO, Brasília, número 23, Janeiro a Junho de 2018, pp. 55-77.

Lei n. 5.172, de 25 de outubro de 1966. (1966). Dispõe sobre o Sistema Tributário Nacional e institui normas gerais de direito tributário aplicáveis à União, Estados e Municípios. Brasília, DF. Recuperado em 15 abril, 2015, de http://www.planalto.gov.br/ccivil_03/leis/L5172.htm

Lei nº 9.718 , de 27 de novembro de 1998. (1998). Altera a Legislação Tributária Federal.. Brasília, DF. $\begin{array}{lllll}\text { Recuperado } & \text { em } & 20 & \text { abril, } & 2015,\end{array}$ http://www.planalto.gov.br/ccivil_03/leis/L9718compilada.htm

Lei n. 11.941, de 27 de maio de 2009. (2009). Altera a legislação tributária federal relativa ao parcelamento ordinário de débitos tributários; concede remissão nos casos em que especifica; institui regime tributário de transição, alterando o Decreto no 70.235, de 6 de março de 1972, as Leis nos 8.212, de 24 de julho de 1991, 8.213, de 24 de julho de 1991, 8.218, de 29 de agosto de 1991, 9.249, de 26 de dezembro de 1995, 9.430, de 27 de dezembro de 1996, 9.469, de 10 de julho de 1997, 9.532, de 10 de dezembro de 1997, 10.426, de 24 de abril de 2002, 10.480, de 2 de julho de 2002, 10.522, de 19 de julho de 2002, 10.887, de 18 de junho de 2004, e 6.404, de 15 de dezembro de 1976, o Decreto-Lei no 1.598, de 26 de dezembro de 1977, e as Leis nos8.981, de 20 de janeiro de 1995, 10.925, de 23 de julho de 2004, 10.637, de 30 de dezembro de 2002, 10.833, de 29 de dezembro de 2003, 11.116, de 18 de maio de 2005, 11.732, de 30 de junho de 2008, 10.260, de 12 de julho de 2001, 9.873, de 23 de novembro de 1999, 11.171, de 2 de setembro de 2005, 11.345, de 14 de setembro de 2006; prorroga a vigência da Lei no 8.989, de 24 de fevereiro de 1995; revoga dispositivos das Leis nos 8.383, de 30 de dezembro de 1991, e 8.620, de 5 de janeiro de 1993, do Decreto-Lei no 73, de 21 de novembro de 1966, das Leis nos 10.190, de 14 de fevereiro de 2001, 9.718, de 27 de novembro de 1998, e 6.938, de 31 de agosto de 1981, 9.964, de 10 de abril de 2000, e, a partir da instalação do Conselho Administrativo de Recursos Fiscais, os Decretos nos 83.304, de 28 de março de 1979, e 89.892, de 2 de julho de 1984, e o art. 112 da Lei no 11.196, de 21 de novembro de 2005; e dá outras providências. Brasília, DF. Recuperado em 12 janeiro, 2015, de http://www.planalto.gov.br/ccivil_03/_ato20072010/2009/lei/111941.htm

Lei n. 12.249, de 11 de junho de 2010. (2010). Institui o Regime Especial de Incentivos para o Desenvolvimento de Infraestrutura da Indústria Petrolífera nas Regiões Norte, Nordeste e Centro-Oeste - REPENEC; cria o Programa Um Computador por Aluno - PROUCA e institui o Regime Especial de Aquisição de Computadores para Uso Educacional - RECOMPE; prorroga benefícios fiscais; constitui fonte de recursos adicional aos agentes financeiros do Fundo da 
Artigo original

Hegemonia - Revista Eletrônica do Programa de Mestrado em Direitos Humanos, Cidadania e Violência/Ciência Política do Centro Universitário Unieuro

ISSN: 1809-1261

UNIEURO, Brasília, número 23, Janeiro a Junho de 2018, pp. 55-77.

Marinha Mercante - FMM para financiamentos de projetos aprovados pelo Conselho Diretor do Fundo da Marinha Mercante - CDFMM; institui o Regime Especial para a Indústria Aeronáutica Brasileira-RETAERO; dispõe sobre a Letra Financeira e o Certificado de Operações Estruturadas; ajusta o Programa Minha Casa Minha Vida - PMCMV; altera as Leis nos 8.248, de 23 de outubro de 1991, 8.387, de 30 de dezembro de 1991, 11.196, de 21 de novembro de 2005, 10.865, de 30 de abril de 2004, 11.484, de 31 de maio de 2007, 11.488, de 15 de junho de 2007, 9.718, de 27 de novembro de 1998, 9.430, de 27 de dezembro de 1996, 11.948, de 16 de junho de 2009, 11.977, de 7 de julho de 2009, 11.326, de 24 de julho de 2006, 11.941, de 27 de maio de 2009, 5.615, de 13 de outubro de 1970, 9.126, de 10 de novembro de 1995, 11.110, de 25 de abril de 2005, 7.940, de 20 de dezembro de 1989, 9.469, de 10 de julho de 1997, 12.029, de 15 de setembro de 2009, 12.189, de 12 de janeiro de 2010, 11.442, de 5 de janeiro de 2007, 11.775, de 17 de setembro de 2008, os Decretos-Leis nos 9.295, de 27 de maio de 1946, 1.040, de 21 de outubro de 1969, e a Medida Provisória no 2.158-35, de 24 de agosto de 2001; revoga as Leis nos 7.944, de 20 de dezembro de 1989, 10.829, de 23 de dezembro de 2003, o Decreto-Lei no 423, de 21 de janeiro de 1969; revoga dispositivos das Leis nos 8.003, de 14 de março de 1990, 8.981, de 20 de janeiro de 1995, 5.025, de 10 de junho de 1966, 6.704, de 26 de outubro de 1979, 9.503, de 23 de setembro de 1997; e dá outras providências. Brasília, DF. Recuperado em 12 janeiro, 2015, de http://www.planalto.gov.br/ccivil_03/_ato2007-2010/2010/lei/112249.htm

Lei n. 12.865, de 9 de outubro de 2013. (2013). Autoriza o pagamento de subvenção econômica aos produtores da safra 2011/2012 de cana-de-açúcar e de etanol que especifica e o financiamento da renovação e implantação de canaviais com equalização da taxa de juros; dispõe sobre os arranjos de pagamento e as instituições de pagamento integrantes do Sistema de Pagamentos Brasileiro (SPB); autoriza a União a emitir, sob a forma de colocação direta, em favor da Conta de Desenvolvimento Energético (CDE), títulos da dívida pública mobiliária federal; estabelece novas condições para as operações de crédito rural oriundas de, ou contratadas com, recursos do Fundo Constitucional de Financiamento do Nordeste (FNE); altera os prazos previstos nas Leis no 11.941, de 27 de maio de 2009, e no 12.249, de 11 de junho de 2010; autoriza a União a contratar o Banco do Brasil S.A. ou suas subsidiárias para atuar na gestão de recursos, obras e serviços de engenharia relacionados ao desenvolvimento de projetos, modernização, ampliação, construção ou reforma da rede integrada e especializada para atendimento da mulher em situação de violência; disciplina o documento digital no Sistema Financeiro Nacional; disciplina a transferência, no caso de falecimento, do direito de utilização privada de área pública por 
Artigo original

Hegemonia - Revista Eletrônica do Programa de Mestrado em Direitos Humanos, Cidadania e Violência/Ciência Política do Centro Universitário Unieuro

ISSN: 1809-1261

UNIEURO, Brasília, número 23, Janeiro a Junho de 2018, pp. 55-77.

equipamentos urbanos do tipo quiosque, trailer, feira e banca de venda de jornais e de revistas; altera a incidência da Contribuição para o PIS/Pasep e da Cofins na cadeia de produção e comercialização da soja e de seus subprodutos; altera as Leis nos 12.666, de 14 de junho de 2012, 5.991, de 17 de dezembro de 1973, 11.508, de 20 de julho de 2007, 9.503, de 23 de setembro de 1997, 9.069, de 29 de junho de 1995, 10.865, de 30 de abril de 2004, 12.587, de 3 de janeiro de 2012, 10.826, de 22 de dezembro de 2003, 10.925, de 23 de julho de 2004, 12.350, de 20 de dezembro de 2010, 4.870, de 1o de dezembro de 1965 e 11.196, de 21 de novembro de 2005, e o Decreto no 70.235, de 6 de março de 1972; revoga dispositivos das Leis nos 10.865, de 30 de abril de 2004, 10.925, de 23 de julho de 2004, 12.546, de 14 de dezembro de 2011, e 4.870, de 1o de dezembro de 1965; e dá outras providências. Brasília, DF. Recuperado em 12 janeiro, 2015, de http://www.planalto.gov.br/ccivil_03/_ato2011-2014/2013/lei/112865.htm

Medida Provisória n. 2.158-35, de 24 de agosto de 2001. (2001). Altera a legislação das Contribuições para a Seguridade Social - COFINS, para os Programas de Integração Social e de Formação do Patrimônio do Servidor Público - PIS/PASEP e do Imposto sobre a Renda, e dá outras providências. Brasília, DF. Recuperado em 25 fevereiro, 2015, de http://www.planalto.gov.br/ccivil_03/mpv/2158-35.htm

Mendes, G. R. (2012). Controles sobre renúncias de receita: quadro atual e oportunidades de aperfeiçoamentos. Monografia Especialização em Orçamento Público do Instituto Serzedello Corrêa - ISC, Tribunal de Contas da União, Brasilia, DF, Brasil. Recuperado em 12 abril, 2015, de http://portal2.tcu.gov.br/portal/docs/2293025.PDF

Morais, C.; Macedo, L. \& Borges, R. (2011). O Resultado Arrecadatório do REFIS, do PAES e do PAEX e seu Impacto na Sensação de Risco Subjetivo pelos Devedores. Monografia do Curso de Administração Tributária da Escola de Administração Fazendária - ESAF, Brasília, DF, Brasil.

Normas Brasileiras de Contabilidade do Setor Público - NBC-TSP 16.11. (2011). Subsistema de Informação de Custos no Setor Público. Brasília, DF. Recuperado em 25 março, 2015, de http://portalcfc.org.br/wordpress/wp-content/uploads/2013/11/setor_publico.pdf

Paes, N. (2011). O Hiato Tributário do Imposto sobre Produtos Industrializados - Evidências Setoriais. Revista Brasileira de Economia de Empresas. 11 (2), 41-53. 
Artigo original

Hegemonia - Revista Eletrônica do Programa de Mestrado em Direitos Humanos, Cidadania e Violência/Ciência Política do Centro Universitário Unieuro

ISSN: 1809-1261

UNIEURO, Brasília, número 23, Janeiro a Junho de 2018, pp. 55-77.

Paes, N. (2012). O Parcelamento Tributário e seus Efeitos sobre o Comportamento do Contribuinte. Revista Economia - ANPEC, 13(2), 345-363.

Paes, N. (2014). Os Efeitos dos Parcelamentos sobre a Arrecadação Tributária. Estudos Econômicos, 44(2), 323-350.

Pronunciamento Técnico CPC 25, aprovado em 26 de junho de 2009. (2009). Provisões, Passivos Contingentes e Ativos Contingentes. Brasília, DF. Recuperado em 08 outubro, 2015, de http://static.cpc.mediagroup.com.br/Documentos/304_CPC_25_rev\%2006.pdf

Saravia, E. (2006). Introdução à Teoria da Política Pública. In Saravia, E. \& Ferrarezi, E. (Coord.). Políticas públicas. (vol. 1, pp.21-42). Brasília: ENAP.

Tribunal de Contas da União. (2011). Relatório e Parecer Prévio sobre as Contas do Governo da República. Exercício de 2011. Recuperado em 25 maio, 2015, de http://portal3.tcu.gov.br/portal/page/portal/TCU/comunidades/contas/contas_governo/Cont as2011/index.html

Tribunal de Contas da União. (2012). Relatório e Parecer Prévio sobre as Contas do Governo da República. Exercício de 2012. Recuperado em 25 maio, 2015, de http://portal3.tcu.gov.br/portal/page/portal/TCU/comunidades/contas/contas_governo/Cont as2012/index.html

Tribunal de Contas da União. (2013). Relatório e Parecer Prévio sobre as Contas do Governo da República. Exercício de 2013. Recuperado em 25 maio, 2015, de http://portal3.tcu.gov.br/portal/page/portal/TCU/comunidades/contas/contas_governo/Cont as2013/index.html

Tribunal de Contas da União. (2014). Relatório e Parecer Prévio sobre as Contas do Governo da República. Exercício de 2014. Recuperado em 25 maio, 2015, de http://portal3.tcu.gov.br/portal/page/portal/TCU/comunidades/contas/contas_governo/Cont as2014/index.html 